\title{
Enriching Everyday Lived Experiences in Dementia Care
}

\author{
Maarten Houben \\ Department of Industrial Design, \\ Eindhoven University of Technology, \\ Eindhoven, the Netherlands \& Tranzo, \\ School of Social and Behavioral \\ Sciences, Tilburg University, the \\ Netherlands \\ m.houben1@tue.nl

\section{Gail Kenning} \\ University of New South Wales, \\ Sydney, Australia \\ gail.kenning@unsw.edu.au
}

\author{
Rens Brankaert \\ Department of Industrial Design, \\ Eindhoven University of Technology \\ \& School for Allied Health \\ Professions, Fontys University of \\ Applied Sciences, Eindhoven, the \\ Netherlands \\ r.g.a.brankaert@tue.nl \\ Inge Bongers \\ Tranzo, School of Social and \\ Behavioral Sciences, Tilburg \\ University, the Netherlands \\ inge.bongers@ggze.nl
}

\author{
Emma Dhaeze \\ Luckt B.V., Eindhoven, the \\ Netherlands \\ e.dhaeze@luckt.nl
}

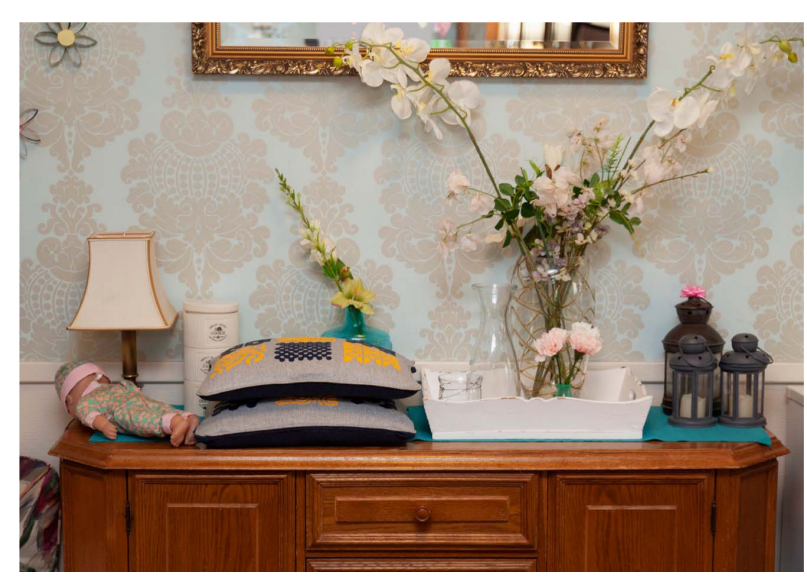

Figure 1: VITA is an interactive sound cushion to play audio content in the everyday care environment.

\begin{abstract}
Research in $\mathrm{HCI}$ is increasingly investigating the role of technology in supporting meaningful and social activities to enhance the lived experiences of people with dementia. However, to further enrich the daily experiences in care, more insight is needed into how technology can directly promote social participation and pleasurable experiences in everyday care situations. This paper discusses the deployment of VITA and SAM: two research products that address the social and emotional needs of residents in day-to-day dementia care. We report how both products offered aesthetic and sensory enrichment, created new experiences in the everyday, and were integrated into the care environment. Furthermore, we identify implications for design to provide: 1) aesthetics in care, 2) authentic
\end{abstract}

Permission to make digital or hard copies of part or all of this work for personal or classroom use is granted without fee provided that copies are not made or distributed for profit or commercial advantage and that copies bear this notice and the full citation on the first page. Copyrights for third-party components of this work must be honored.

For all other uses, contact the owner/author(s).

TEI '22, February 13-16, 2022, Daejeon, Republic of Korea

(c) 2022 Copyright held by the owner/author(s).

ACM ISBN 978-1-4503-9147-4/22/02.

https://doi.org/10.1145/3490149.3501326 experiences, 3) reinforcing everyday life, and 4) community-driven use in practice. We contribute to existing research by demonstrating how technology for dementia care can transcend instrumental use and culminate in warm-felt everyday experiences.

\section{CCS CONCEPTS}

- Human-centered computing $\rightarrow$ Human computer interaction (HCI); Empirical studies in HCI.

\section{KEYWORDS}

Dementia, Design, Everyday life, Experience, Research products, Residential care

\section{ACM Reference Format:}

Maarten Houben, Rens Brankaert, Emma Dhaeze, Gail Kenning, Inge Bongers, and Berry Eggen. 2022. Enriching Everyday Lived Experiences in Dementia Care. In Sixteenth International Conference on Tangible, Embedded, and Embodied Interaction (TEI '22), February 13-16, 2022, Daejeon, Republic of Korea. ACM, New York, NY, USA, 13 pages. https://doi.org/10.1145/3490149. 3501326 


\section{INTRODUCTION}

Dementia is an umbrella term for conditions related to significant cognitive changes that negatively affect memory, orientation, and judgment [75]. The number of people with dementia requiring professional care increases rapidly, adds pressure to overburdened care systems and increases the workload for professional caregivers [1]. As a result, people with dementia living in care facilities can experience a lack of social engagement and meaningful experiences [99]. Researchers in the HCI community are currently investigating how technology and design can enhance the lived experiences of people with dementia and their caregivers in residential care $[4,13,69,76]$. This body of research has shifted perspectives of people with dementia from addressing perceived cognitive and physical disabilities to acknowledging them as individuals with unique lived experiences $[4,66,78,109]$. Therefore, there is an increased research interest in technologies that enrich subjective experiences by offering sensory stimulation [49, 54, 92], enabling people with dementia to make social contributions in their environment $[38,79,110]$, and exploring and maintaining selfhood and identity $[4,66,108,109]$.

Enriching opportunities for people with dementia often take form as planned activities and scheduled exercises [16] such as music sessions [41, 89], reminiscence activities [90,111], or art therapy. For instance, sensory enrichment is often limited to scheduled activities that need to be facilitated by the care staff in specially equipped multisensory rooms [22, 91]. Therefore, the participation of people with dementia in meaningful activities often relies on the availability of care staff and planned social or recreational programming [99]. As a result, people with dementia often withdraw from everyday social interactions and risk being socially disconnected from others and themselves [52]. For example, time gaps in-between scheduled activities of the recreational program and care tasks can cause boredom, restlessness, and sleeping during the day, which disrupts sleep patterns for care home residents [55]. There are opportunities for technology to stimulate opportunistic use for spontaneous social engagement and pleasure in everyday moments in care $[38,77,78]$. However, to further explore how technology can enrich the everyday experiences in care settings, more insight is needed into the tangible and experiential qualities that enable technology to transcend instrumental use and promote social participation, curiosity, and pleasurable experiences directly in the care space.

This paper reports the findings of two field studies that aimed to investigate the role of technology in enriching the everyday experiences in dementia care. The first field study investigated the everyday use of an interactive sound cushion named VITA that enabled people with dementia to play sounds and music in a care home environment with a soft textile interface (see Figure 1). The second field study involved the deployment of SAM, a set of two paired multisensorial companions in the communal space of a care home that responded to each other and stimulated social engagement between residents (see Figure 2). In this paper, we refer to VITA and SAM as research products [85] with a high-quality finish that are durable for independent use and contextually fitting in the residential care environment. These two research products aimed to support human and sensory engagement in real-life care practices.

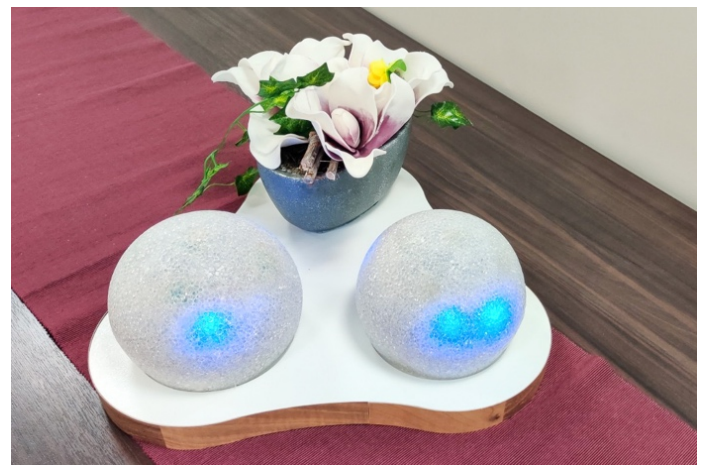

Figure 2: SAM is an interactive companion that plays sounds and displays colors in response to touch-based inputs and can mimic or react to the input of a paired device to stimulate social engagement between care home residents.

The field studies revealed how SAM and VITA offered aesthetic and sensory enrichment, created meaningful experiences in everyday care settings, and integrated into the dementia care environment. This paper focuses on the tangible and experiential qualities that enable the everyday use of VITA and contributes to our earlier work that reports on the responses of residents and caregivers to curated sets of sounds produced by VITA [54]. Furthermore, we present design implications to enhance the everyday lived experience of people in residential dementia care through: 1) aesthetics in care, 2) authentic experiences, 3) reinforcing everyday life, and 4) community-driven use in practice. With these insights, we aim to counter medicalized views of technology in dementia care as being primarily functional or instrumental and address the need to recognize the care home, not as a clinical setting, but as a 'home' of people with dementia by providing comfortable warm experiences for both residents and staff.

\section{BACKGROUND}

\subsection{Dementia in HCI}

Dementia care practices have adopted Person-Centered Care (PCC) approaches with professional caregivers initiating and supporting social relations during everyday care tasks [32] to provide care and support the psychosocial needs of people with dementia [15]. These approaches emerge from the recognition that societal shifts in understanding of care focus on the lived experiences of the condition rather than pathological understandings of the disease [80]. These person-centered approaches parallel the growing interest in Human-Computer Interaction (HCI) in democratizing design by focusing on social outcomes in practice $[2,10,30,73]$. Accordingly, technologies for dementia are re-conceptualized to focus on individual potential and possibility rather than the loss of skills or abilities $[4,65,66,78]$. This ongoing body of work has resulted in numerous prototype developments $[38,49,53,92,107]$ and ethnographic evaluations in residential care settings $[36,66,78,79]$ and motivated Experience-Centered Design research for people with dementia in HCI $[35,38,78,109]$. These works promote socially inclusive practice $[12,48,104]$, empowerment and agency $[38,74,106,110]$ 
and a sense of self and identity [4, 58, 66, 78, 109]. For instance, various studies have illustrated that the evaluation of technology in the care context requires empathy $[88,96]$, reflexivity on the part of the researcher [47, 50, 96], and recognition that residents with dementia are capable of mutual conversations and should be included as such $[36,66]$.

\subsection{Residential Care Setting}

The residential care setting is a challenging research context since these environments need to facilitate people living, working, receiving therapeutic support, performing care duties, and organizing social gatherings [37]. Furthermore, since dementia is progressive, participants' desire and ability to participate in research may differ in residential care compared to other settings [75]. Therefore, formal and informal caregivers, who actively fulfill a role in caring for people with dementia, need to be involved in this research to ensure a safe inclusion and safeguard the participants' integrity $[54,81,106]$. Adopting a reciprocal or mutually rich and intentional approach can be rewarding for researchers and people with dementia [63]. Therefore, recent HCI research in residential dementia care has argued the need for a relational approach and careful consideration of research execution and organization in this sensitive context [29, 36, 54, 92].

Technology can serve as a tool for caregivers in residential dementia care to initiate social interactions with residents [54], between residents and visitors [110], as well as spark social connectedness among the residents themselves [38, 79]. For example, providing open-ended cues can lead to conversation topics during social activities in the care home [38]. Digital media can provide multisensorial stimulation and cues to evoke emotional responses and support social activities in the care home [39], such as images $[3,44,101]$, videos $[24,92]$, virtual reality $[49,97]$ or audio-content $[54,79]$. Technology can provide an accessible interface to access these various forms of digital media, for example, semi-public displays [34, 72, 92, 101], accessible audio-players [54, 100], and digital touchscreens $[3,44]$. This established body of knowledge demonstrates the benefits of technologies that can increase social belonging and connectedness in care home settings [38, 54, 92, 101, 110]. However, it remains challenging to channel design research into the everyday environment of people living with dementia [13].

\subsection{Tangible Artefacts in Dementia}

The HCI community has widely adopted research through design approaches in which the evaluation of research artifacts produces knowledge but does not necessarily result in commercial products [113]. Research products refer to design artifacts that are further developed than what may typically be expected of a prototype and are independent and aesthetically developed to seamlessly fit within a real-life research context [85]. The importance of aesthetics in design to facilitate meaningful experiences with technology has been extensively explored $[7,112]$. As such, aesthetics is not merely the object's look and feel and whether it is perceived as attractive or otherwise, but how it is experienced [112]. In the context of dementia, aesthetic experiences that focus on bespoke and intimate design artifacts can elicit values, beliefs, and insight into the subjective emotional experiences of people with dementia $[43,79,108,109]$.
For example, Wallace et al. used digital jewelry as an intimate and sensitive probe to explore and support a sense of personhood and identity in dementia [109]. Furthermore, tangible and multisensorial designs can support embodied in-the-moment activities for people with dementia by making use of their remaining sensorial skills [28, 43]. For instance, mirroring vibrotactile feedback can provide nonverbal embodied communication between people with advanced dementia and their relatives [93]. Furthermore, simple interactions fitted to the sensorimotor skills of people with dementia with familiar and tangible objects can spark reminiscence and support 'holding on' to meaningful memories [56]. These works demonstrate the potential of tangible probes and research products to provide a lens into the subjective lived experiences of dementia and enrich these experiences.

\section{TWO FIELD STUDIES}

We report the insights from the in-context deployments of two research products, VITA and SAM, that aimed to support social participation and sensory stimulation in the care space to provide a more general and nuanced view of how technology can enrich everyday residential dementia care. The participants with dementia involved in both field studies lived permanently in the care homes and were diagnosed with mid to advanced stages of dementia. VITA and SAM are non-commercial prototypes codeveloped within individual collaborations with two different care organizations. Both devices were developed prior to the field studies as part of multidisciplinary research projects between care practice, researchers, people with dementia, and their relatives. As a result of this collaboration with practice, both devices are durable research products [85] developed to be deployed in the care facilities and are currently still in use within the involved care organizations. Therefore, both cases contribute to this paper's research question to build knowledge concerning the role of technology to enhance everyday experiences in residential dementia care.

\subsection{Field Study 1: Role of Sound in Everyday Care Routines}

Study 1 was grounded in a large body of research [5, 41, 89] on how music or meaningful sounds can support reminiscence $[39,53$, $62,68,95]$, positive emotions or pleasure [57], social interactions $[41,46,53,71,79]$, and stimulate the exploration and manifestation of identity and selfhood in dementia $[6,45,79]$. The first field study aimed to explore how these beneficial effects of sound could be leveraged into care environments for people with dementia [54].

3.1.1 VITA Sound Cushion. VITA is an interactive sound cushion for people with dementia to play meaningful audio content such as music, soundscapes, or voice recordings together with their relatives and caregivers. People with dementia can play audio recordings by touching a touchpad on the cushion, as the corresponding sound starts to play until the person stops touching it. These touchpads are colorful patterns embroidered on the pillowcase with conductive sensors underneath to detect physical touch.

VITA was designed (see Figure 3) with contrasting colors such as bright yellow and dark blue to be perceived better by people with dementia, as confirmed by literature [84]. The pillowcase was made from a medical fabric that is waterproof, non-toxic, non-allergenic, 


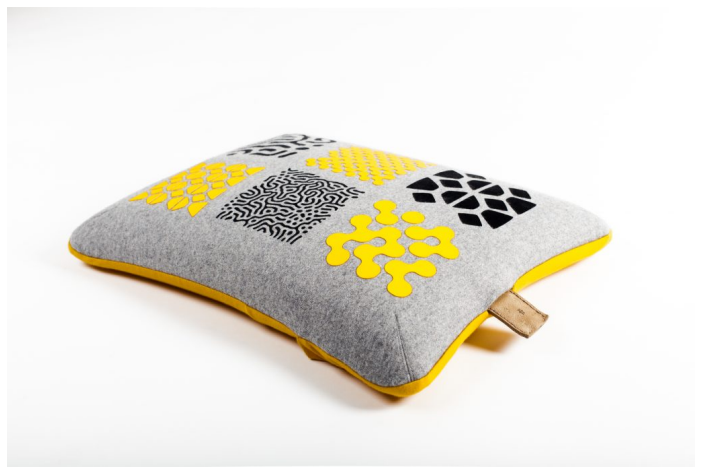

Figure 3: VITA is a cushion equipped with conductive textile sensors that offer a touch-based input for playing audio content.

durable, and able to be sterilized and removed to be washed for hygienic reasons. VITA contains a high-density foam as pillow filling to ensure a sturdy but tactile soft interface that can be used on flat surfaces, such as on a table, on a resident's lap, or in bed. The speaker and electronic circuit board of the pillow are safely concealed within the pillow filling.

During the study, VITA offered access to both personal and generic audio content [54]. The generic sets represented different themes ranging from playful activating sounds, e.g., a barking dog, to calming quiet soundscapes, e.g., the rainforest. Furthermore, an online portal enabled caregivers and families to gather and select meaningful audio content for the person with dementia. The professional caregivers who facilitated VITA in context could select a user profile to offer personal sounds to the residents. As a result, one cushion catered to various users within the same care setting.

VITA was designed as a cushion to fit the interior of the communal space in the care home and be available for use whenever needed. A resident or caregiver can easily activate VITA when in sleep mode by touching one of the touchpads and playing the sounds. VITA then offers immediate access to a general sound set containing several generic sounds, such as chirping birds or beach sounds. VITA is automatically connected to a server, enabling a personalized experience and control for caregivers via the online interface. The reverse side of VITA contains a control panel for a quick menu selection of volume, user, and sound set. When pressing a button, VITA provides voice feedback to indicate what setting or user is selected. The caregivers can charge the battery of VITA by unzipping the pillowcase, revealing the connection pin to connect the charger.

3.1.2 Deployment of VITA in Two Care Facilities. A field study (S1) with VITA was conducted at two different care facilities and lasted four weeks in each facility [54]. In this study, 19 residents with advanced dementia with conditions such as Alzheimer's disease and vascular dementia participated, together with 16 professional caregivers who facilitated the use of VITA in context. During the field study, in-situ observations were conducted for 18 days during two field evaluations that each lasted four weeks. At the end of the study, ten exit interviews were conducted with caregivers who used VITA. The professional caregivers were either activity coordinators or nursing staff. This field study was approved by the University Ethics Review Board and was evaluated and debriefed at the Client Representation Board of the care organization. Proxy consent was collected from the legal representatives of the residents. In addition, the inclusion of residents in this study was assessed by professional caregivers who provide care to the residents daily. The professional caregivers maintained the duty of care and were always present during observations of the researcher. Therefore, the informed consent was facilitated as process consent [27] based on the residents' responses through a continuous dialogue between residents, caregivers, and researchers.

\subsection{Field Study 2: Increasing Social Interactions in Communal Areas}

Field study 2 was set in the communal living area to address the experiences of residents who displayed passive behavior and apathy towards each other. This lack of initiative in social interactions or withdrawal from activities of daily living is negatively associated with quality of life in the care home [83]. Therefore, we explored in study 2 how multisensory stimuli can facilitate playful and engaging moments at the table in the communal space of a care home to counteract passive moments, such as between lunch and an afternoon activity or after dinner.

3.2.1 SAM Interactive Companion. SAM is a table companion for residents sitting in the communal space of the care home. SAM was designed as a semi-transparent sphere that can change color, vibrate, and play sounds to provide multisensory stimuli for the residents to draw their attention and invite them to engage with it. SAM is made from a flexible plastic material that is soft to the touch, safe to use, and can transfer tactile feedback. The semi-transparent plastic material also diffuses the light from the LEDs, resulting in a softly lit sphere. The spherical shape is comfortable to hold and affords multiple touch-based inputs as residents can hold, stroke, tap, or shake SAM (see Figure 4). Based on how the residents interact with SAM, it will play sounds, change color, or vibrate accordingly. When SAM is not being used, it will make a sound and give a different light animation every ten minutes to draw attention and invite residents to interact. For each SAM, different themes can be selected, which is a matching collection of sounds. SAM contains four different themes during the study: spring, dog, Tibetan singing bowl, and robot. For instance, the spring theme includes the sounds of singing birds and croaking frogs. SAM's behavior was displayed through colored lighting and pulsating vibrations based on the interactions of the resident. For instance, by stroking SAM when set in the spring theme, the user can hear birds singing while the light slowly pulsates from a white to pink color. However, when tapping SAM, residents can hear a croaking frog, and SAM turns green.

Two SAM devices are connected as one SAM device reacts to input on the paired device to offer a sense of connection between the residents holding SAM and provide a continuity of sensory stimuli that evokes curiosity and invites residents to respond. When SAM responds to a user's input, it sends a signal to the other paired SAM device that responds or mimics the reaction. For example, when one SAM is used, and the other paired device is not, the unused device displays a 'jealous' behavior by turning red and playing a 


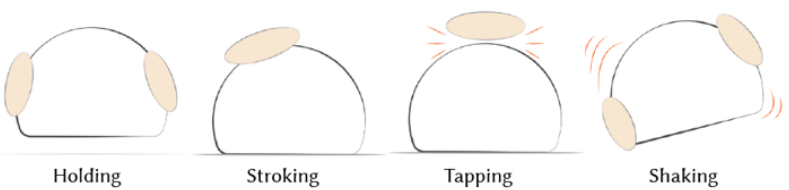

Figure 4: SAM responds to actions such as holding, stroking, tapping, or shaking.

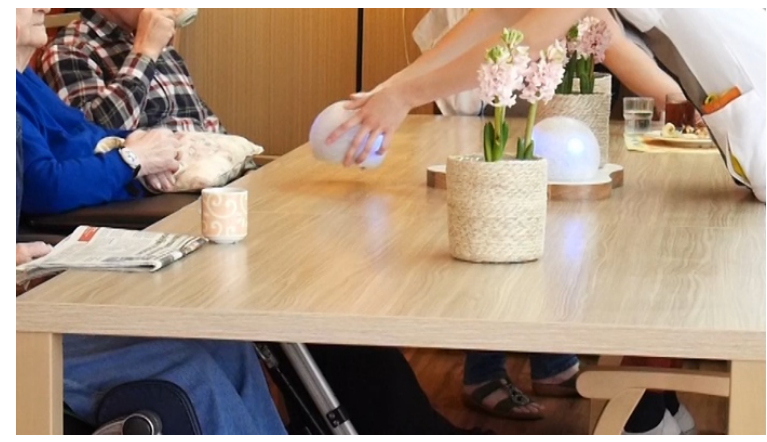

Figure 5: SAM is part of the everyday environment and is available for spontaneous use in the care space.

sound based on the selected theme. If both SAMs are used at the same time, both devices will mimic each other. For instance, if two residents are holding a SAM, and one resident shakes SAM, it will vibrate and display a yellow color, after which the other SAM device will also vibrate and display the same color.

During the day, SAM was placed on a table as a centerpiece (see Figure 5) in the communal living area to be available for use in the care space and to blend into the interior of the communal living area. SAM can be easily charged wirelessly by placing it on a separate charging station out of reach of the residents in the staff room. The caregivers place SAM on the table centerpiece in the morning and place it back on the charging station in the evening so the battery can be charged overnight. The charging station also contains the interface for the care staff to select a different theme or adjust the volume when desired.

3.2.2 Deployment of SAM in the Communal Space. SAM was deployed for one week in two care units in a long-term residential care environment and used by people in mid to advanced stages of dementia, with conditions such as Alzheimer's disease, frontotemporal dementia, Lewy bodies, or vascular dementia. Exit interviews were conducted with 11 professional caregivers and two family members. Similar to the study with VITA, the professional caregivers also consisted of activity coordinators and nursing staff. During this period, SAM was free to use by residents and care staff during everyday moments and situations in the communal living area. The evaluation methodology used qualitative data collection approaches, including observational field notes, five semi-structured interviews with professional caregivers, and three semi-structured interviews with family members who used SAM. After the deployment of SAM, questionnaires were distributed to gain insights into the care staff's overall experience on SAM, potential points for improvement, and the added value for the residents. The questionnaires consisted of open-ended questions on 1) overall experience; 2) the experience of the resident in terms of added value, social connection, interaction, and impact; 3) use and potential for visiting family members; 4) integration in practice, ease-of-use, and added value for professional caregivers. The topic list guiding the interviews contained the same question types as the questionnaires, but the interviewer also asked relevant follow-up questions. In total, eight questionnaires were received from professional caregivers participating in the study. Approval for this field study was granted by the care organization involved in the development of SAM. Informed consent was collected from the participating caregivers and family members, who commented on their engagement with SAM. Similar to the study with VITA, the inclusion of residents was assessed by the professional caregivers involved in the study who were always present during the use of SAM in context. The process consent [27] was based on the willingness of the residents to interact with SAM in the communal space in dialogue with the professional caregivers who ensured residents felt safe, informed, and comfortable. The field study was closely monitored by the professional caregivers involved in the study, higher management of the care home, and other professional caregivers from the organization.

\subsection{Data Analysis}

All data was processed confidentially and stored in a pseudoanonymized form by a number and the participants did not appear recognizable on the photographic documentation. The data of both field studies were analyzed separately, and the first author conducted a thematic analysis using an inductive approach for each study by coding quotes from the observational field notes, questionnaires, and interview transcripts based on frequency and reoccurrence [14]. The codes were developed into concepts relevant to the research question of this paper, namely the tangible and experiential qualities of SAM and VITA that contributed to social participation and meaningful experiences in everyday care practice. The first author compared the themes and codes from the separate analyses of both research products and developed new themes by linking patterns and reoccurrence of the themes from both studies. The final analysis was discussed and iterated in consultation with all coauthors.

To facilitate transparency regarding the thematic analysis, we report on our positionality based on the research experiences and involvement in both research projects. All authors have extensive research experience in the context of dementia or have personally engaged with people with dementia. The first author collected the data for the field study with VITA and was not involved in the design and development of VITA and SAM. The second author supervised the development of SAM and VITA. The third author guided the design process of SAM, was involved in the design of SAM itself and collected the data for the field study.

\section{FINDINGS}

We report on the qualitative data on how the deployment of VITA and SAM resulted in 1) aesthetic and sensory enrichment, 2) creating new experiences in the everyday, and 3) integration in the care environment. We refer respectively to study 1 and 2 as (S1) 
and (S2), and the presented qualitative data consists of field notes from the observed responses of the residents during the deployment (S\#_fieldnote) and quotes from the exit interviews and written statements from the questionnaires from the caregivers (S\#_C\#).

\subsection{Aesthetic and Sensory Enrichment}

In this section, we report the responses of the residents and caregivers related to how the physical devices were perceived and how this offered aesthetic and sensory enrichment in the care context.

4.1.1 Multisensory Cues to Stimulate Participation. The colorful and finished look of VITA sparked interest in the residents living with dementia to use the device. Residents explicitly stated that they appreciated the aesthetics of VITA, as described in the field notes: "Is that really for me?" asks a resident. The caregiver responds: "that belongs to all of us, but you can use it." "Yes?" asks the resident as she picks up the pillow and explores the device: "it is beautiful!" I [researcher] ask the resident: "do you think it is a nice pillow?" She nods and replies: "I think it is really beautiful that thing!'” (S1_fieldnote). The caregivers also appreciated the aesthetics of VITA, such as the bright colors and contrast of the vinyl patterns on the pillowcase to attract the attention from the residents: "yellow comes up nicely, and in contrast to that blue, gray is also soothing, it is not too much" (S1_C4).

By providing multisensorial stimuli such as sound or lights, VITA and SAM stimulated and invited the residents to interact with the devices, as was observed by a family member of the resident: "You can see that [name resident] is triggered by SAM. Because the lights keep going on and off, [in] different colors, it does stimulate [the residents in general]" (S2_F1). According to the professional caregivers, the bright colors of SAM (see Figure 6) and the playful sounds emerging from the device were vital in bringing forward an interest in the residents for using SAM: "It attracts people's attention through the sounds and colors" (S2_C8). For instance, one caregiver reported that when SAM was in rest mode and would not display any colors, it often failed to draw the attention of the residents: "I think that if those lights are not on or without sounds, it is not really attractive for the residents" (S2_C16). These examples indicate the value of multi-sensorial output for stimulating participation with this target group.

4.1.2 Tangible Qualities. The form of the VITA cushion afforded different ways to use the product within the care context. It was observed how VITA was used in various settings, such as on the table and the residents' lap: 'the caregiver is sitting on the couch together with the resident in her room and places VITA on the lap of the resident. As the resident places her hand on VITA, the caregiver puts her hand on top of hers as a sound is heard. The resident answers: "Nice!" as the caregiver responds: "Shall we try another one [sound]?" (S1_fieldnote). As VITA is a portable device, it was used in various settings in the care home outside the communal space or activity rooms. For instance, one of the residents was bedridden, and VITA was used as a tool during a one-on-one care activity that caregivers conducted at the resident's bed: 'The resident is lying curled up in bed with his knees bent slightly upwards. The caregiver gives VITA to the resident and rests the pillow on his legs, slightly vertically. The resident begins to explore VITA and hears the church sounds'

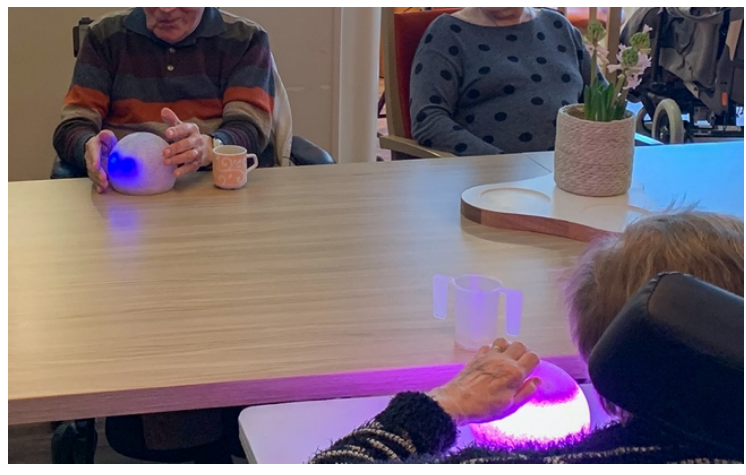

Figure 6: SAM offers multisensory stimuli, such as colored lights, sounds, and vibrations, to draw the attention of people with dementia.

(S1_fieldnote). However, this setting also revealed requirements in terms of weight; when VITA was used on the laps of several residents, caregivers indicated that VITA was too heavy: "It is good for on the table, but for example, with one resident [who is bedridden], I had to tilt the pillow and then it is a bit heavy." (S1_C5).

Caregivers noted after the study that VITA was too firm and they preferred a softer version: "I think the pillow is good, but for [name resident], the pillow is too hard. Also, to hold it. She loves stuffed animals. Those are soft. And this was hard when holding it and laying her hand on it, so she just leaves it." (S1_C14). Lastly, caregivers appreciated how the pillowcase of VITA was washable and waterproof for extensive use within a dementia care context: "Especially if it's for everyone, that you can keep it hygienic" (S1_C7), showing that the form and material should also be practical.

The spherical shape of SAM was considered attractive by the caregivers as they reported how the form helped to draw the attention of the residents in the communal space during the deployment: "The residents also find SAM attractive. Perhaps also because of such a shape" (S2_C3). The spherical form of SAM allowed it to be held in the hands of the residents that enabled personal forms of interaction: "you can easily put your hands around it" (S2_C4). Furthermore, the spherical shape also contributed to the interaction, as it was considered to cause the product to be more inviting: "a sphere in itself is just pleasant and looks nice. It is not a hard thing. I think that appeals" (S2_C2). On the contrary, the caregivers also noted that the sphere was too tricky for certain residents to hold in their hands. Especially for residents who experience challenges with motor skills to hold the research product: "I used it with a lady who is in a wheelchair, further into dementia [in later stages of dementia], there you notice that she does not have enough strength in her hands and that SAM does nothing [for her]" (S2_C5).

4.1.3 Childish vs. Stimulating. Concerning the role and function of VITA in the care setting, caregivers noted that it was perceived as childish by some residents that were in the moderate stages of dementia and were considered cognitively too well for VITA: "Those are people who are not far enough in their dementia in that respect, they are like, 'what is this strange thing' and 'I do not need it at all,' while others do it very differently and are really, completely immersed so to say [heavily engaged by VITA]" (S1_C8). This was also 
observed when a resident who recently moved into the care home used VITA and considered it more useful for the other residents: "Beautiful and very important for some people [...] quite pleasant for the people here, think it is calming for some" (S1_fieldnote). Furthermore, the use of VITA also seemed to depend on the willingness of participants to interact with it, which might be affected by their previous life experiences and personal associations with the technology: "he was a bank manager, and he easily finds things a bit too childish" (S1_C8). Furthermore, caregivers noted there could be a gender bias with men not wanting to interact with a cushion: "I do think that the women respond more than the men because they [the men] quickly have something like: 'I will not participate.”' (S1_C4). Similarly, the results from SAM show that the system could have more value for people in later stages of dementia for similar reasons as described above, as one resident who used SAM stated: "I do not see myself stroking such a ball every day" (S2_fieldnote). Therefore, interventions oriented to stimulate the senses are likely to be more successful for people with dementia in the later stages: "if you are still quite good, then you are also like 'what should I do with it.' But if you are already in a further stage, then that is nice because of all the stimuli that you get" (S2_C4).

\subsection{Creating New Experiences in the Everyday}

In this section, we focus on the responses related to new experiences evoked by VITA and SAM. These results show how both research products stimulated exploration, discovery, and open-ended engagement.

4.2.1 Stimulating Exploration and Discovery. The observations of VITA revealed how residents took the initiative in exploring the various sounds by interacting with the six touchpads. It was observed how residents fiddled with the embroidered patterns with their fingertips and felt, sometimes profoundly focused, around the edges of the cushion and explored the material with their hands: 'The resident's first reaction is to feel vinyl patterns of VITA with her fingertips and follow the lines of the pattern. The caregiver asks her what she thinks, to which she replies briefly: "very beautiful!"' (S1_fieldnote). Caregivers indicated how the texture of the vinyl relief with subtle height differences of the embroidered patterns of the touchpads encouraged residents to touch and feel the materials and fiddle with the vinyl (see Figure 7), illustrating how the material contributes to discovering the product and encouraging use: "the relief is cleverly designed because it motivates them to keep touching and feeling [the material of] VITA" (S1_C5).

Similarly, SAM offered an easy-to-use interface as the residents could hold the spheres in their hands: "Often they use both hands for both SAM devices. One hand for one SAM and the other hand for the other SAM" (S2_C4). Input from simple actions such as holding, tapping, or stroking, was translated into output in the form of sounds, colors, and vibrations to further stimulate the use of SAM by the residents: "And it is also that they feel it themselves and are working on it [to] try out other sounds" (S2_C3). As such, both research products revealed how the simple interface contributed to stimulating exploration and discovery that could result in new social encounters, as was observed how: "a resident taps SAM and starts a conversation about it with another lady sitting in the communal area [...] Another resident participates in the discussion about SAM"

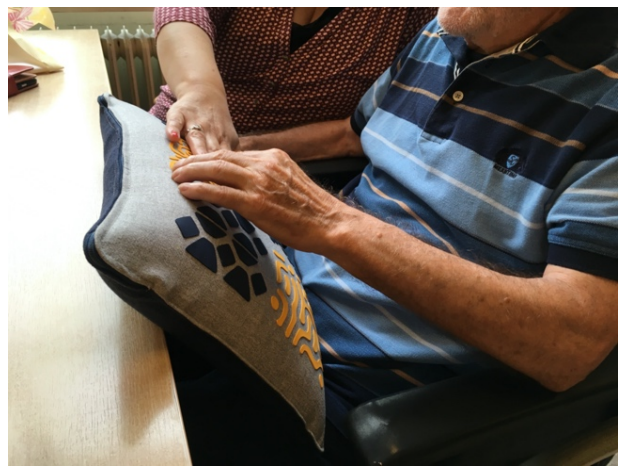

Figure 7: The embroidered patterns on VITA sparked interest in the residents in using the device.

(S2_fieldnote). These examples illustrate how the residents became curious in response to both devices in the care environment.

4.2.2 Open-Ended Engagement. Six residents explicitly recognized how they perceived the sounds as a result of their interaction with VITA: 'A resident says "Yes, I hear what comes out of that [VITA]"' (S1_fieldnote). However, several residents seemed not to realize that sounds originated from VITA and started to search for the sound source in their surroundings: 'upon hearing the sound of rain she looks around her, then behind me [the researcher] as if she is looking for something' (S1_fieldnote). Furthermore, residents stated that they found it strange that sounds emerged from a cushion: 'She stared at the pillow and turned to me and says, "It is a strange thing that it is in a pillow..." and smiles at me [the researcher]' (S1_fieldnote).

Similarly, the connection between the paired SAM devices was not always clear: "The residents do not realize that Sam is connecting [to the other SAM]." (S2_C15), and the different interaction behaviors of SAM was also challenging to understand for some of the residents: "He does not understand that SAM reacts to the way it is used, like when SAM becomes 'jealous"' (S2_F2). However, caregivers also stated that it is not necessary that all residents fully understand the concept of SAM as it still provides a positive experience for them: "Does it matter that they do not necessarily notice? They see colors change, they hear sounds, they feel vibrations" (S2_C1). For instance, it was observed how the sounds that emerged from SAM started a conversation: 'a resident looks outside at the birds when SAM makes a sheep noise, and she begins to talk about past experiences of encountering farm animals.' (S2_fieldnote). The responses that are evoked by SAM, such as being stimulated, laughing, or talking was considered more meaningful than understanding the connection itself: "I enjoy seeing people respond to one stimulus. And how people respond to another cue. [...] If I get that response, get a glow in someone's eyes, I think it is already working. Then it is just fine" (S2_C3). 


\subsection{Integration in Care Environment}

The analysis provides insight into how VITA and SAM were integrated and used in the everyday environment of residential dementia care and how this facilitated the accessibility and direct use of both devices in the care space.

4.3.1 Caregivers as Initiators. In the evaluation of the research products, caregivers stated that they often had to provide explanations and instructions to the residents on how to use VITA: "At first I took the hand of [name resident], and eventually she just imitates you. Then you no longer have to hold her hand, she can just perform [interact with VITA]." (S1_C2). Furthermore, it was also observed how residents explored VITA together with the caregiver to learn how the cushion works and how they can play sounds: "you have to help someone a bit by hand. Usually I would lay hands on it together and that [caused] a certain connection with each other" (S1_C8). Thereby, the professional caregivers were often initiators in using VITA and opening up engagement for the residents with dementia.

Similarly, in the case of SAM, the caregivers indicated residents would not take SAM by themselves, but the caregivers had to offer SAM to the residents. After introducing SAM to the residents, the professional caregivers had to explain how SAM worked and invite the residents to use the system: "They do not do it by themselves. When you give SAM to a resident, you only have to work on it for a moment, and then they get started themselves [...] You have to invest in it, but that makes sense if people do not know it, then you have to help and explain what it is." (S2_C3).

Even with open-ended and straightforward interfaces, the caregiver plays a vital role in inviting and stimulating use. Therefore, the successful use of VITA and SAM in context requires the caregivers to embrace the technology and see the added value in daily care practice: "I am very excited. SAM adds something that enriches contact with people" (S2_C10), suggesting that if caregivers do not support it, they could also hamper the adoption of this type of technology. Therefore, having a community of professional caregivers that are enthusiastic about the technology can further spark the use and adoption with other care staff in the care home: "Many colleagues are very enthusiastic. There are colleagues who prefer to use it with residents during everyday care" (S2_C3).

4.3.2 Direct Availability in the Care Space. The direct availability of VITA and SAM enabled the use of both devices during everyday moments in the care setting. VITA was used by the caregivers who would provide the device to residents spontaneously to counter boredom or unrest in the residents: "Usually you have an activity at fixed times, and then you have just such a restless part in between, I always enjoyed using it [during that time]" (S1_C8). Similarly, the residents appreciated using SAM during everyday moments as one resident stated that: "then we have something to play with" (S2_fieldnote). The care staff mostly used SAM during moments of boredom in between activities: "Yes, you can take it to do something with the people" (S2_C7).

Caregivers appreciated that VITA offered both a physical button interface and an online platform to select user profiles and adjust technical settings. This flexibility catered to caregivers who are familiar with using an app or caregivers who preferred a simple interface, as VITA matched different ability levels on the caregiver side as well: "For me, the app was the easiest, but we also have older employees here who have simply never had a smartphone, so I found it both very easy, everyone who does not have a smartphone should also be able to operate it easily. And that was indeed the case." (S1_C2). Several residents also responded to the caregivers' interface, such as watching along with the caregiver using the app, pressing the buttons, or reacting to the voice feedback. The voice feedback of VITA was sometimes confusing for the residents, as was observed by the researcher: 'the caregiver selects the user, and the voice feedback says the user's name. The resident leans forward and says, "Yes, I am here"' (S1_fieldnote). Nevertheless, the button interface enabled the caregivers to use VITA directly in the care space by quickly selecting the correct settings, showing the importance of a simple minimal interface for caregivers: "Yes at the time I thought 'I want to use it now' and then I just tried it that way" (S1_C4).

Similarly, SAM was easy-to-use and available in the communal room as well, so caregivers could quickly grab the device and offer it to a resident during daily practices: "It was an easy system to turn on. You just take it for a resident and put it on the table" (S2_C4). By placing SAM on the table's centerpiece, SAM was allocated a clear space, so the device was always ready, charged, and available to use. As such, meaningful and engaging moments were spontaneously evoked throughout the day in an often-hectic residential care environment: "You know what makes the difference, you do not have to pick it up from a cupboard somewhere. It is already on the table as a table piece, so that makes it easy. Even if you only have 5 or 10 minutes to do something with that resident, it will be done in no time" (S2_C5).

\section{DESIGN IMPLICATIONS}

Based on the findings of the field studies, we discuss implications for designing technologies that aim to enrich everyday experiences in dementia care.

\subsection{Aesthetics in Care}

The results revealed the value of aesthetic artifacts in the context of dementia to spark curiosity, facilitate engagement and generate emotional responses, as people with dementia seek aesthetically satisfying experiences [18]. However, in the context of care, aesthetics often refers to whether technology is perceived as assistive to compensate for lost skills, whether it is reinforcing abilities, or is age and culturally appropriate $[9,19,103]$. The professional caregivers elaborated in the interviews how they would avoid using SAM or VITA with certain participants based on their personal and cultural backgrounds. For instance, this was the case with a former bank manager who often perceived certain activities or products in the care home as child-like.

People in the mid to advanced stages of dementia are often merely viewed as having limited cognitive and motor skills, so products for residential dementia care often come with clinical, medical, or functional aesthetic qualities [4]. In contrast, VITA and SAM had a purpose beyond purely functional technology to support care by allowing for open-ended engagement for small everyday moments that intentionally contribute to social connection and a sense of belonging in the care home. These findings align with 
how technology can support warmth and affection in the care delivery process by stimulating human contact and presence, as well as feelings of comfort and coziness [87]. We argue the need for perspectives on designing for dementia to focus on the aesthetics of the offered experience and align products accordingly. Technology should not only provide accessible interfaces understandable for people with dementia, but also reflect the sensibilities of home [108], community [23], warmth [87], and material attractiveness [79] through careful design [59] of shape, materials, sounds, and touch to create aesthetically-satisfying experiences $[59,63,67,104]$.

\subsection{Authentic Experiences}

With VITA and SAM, we offer contemporary aesthetics to indicate these artifacts are different or novel and should be perceived as such. SAM is a form of companionship in an abstract entity, rather than resembling a pet, as not to intentionally deceive the residents into thinking SAM is a living social being. The spherical design allows for everyone to interpret SAM in their own way and with their unique associations. Allowing the user to bring their understanding of the object facilitates a personalized and authentic perception for people with dementia $[21,53,54,101]$. Our results indicated that the residents with dementia could not always deduce how the research products worked logically. For example, not all residents understood at first that the sounds were emerging from VITA. People with dementia can have difficulties with the spatial processing of sound [42], and careful consideration and support are needed to avoid that audio cues are being perceived as auditory hallucinations [105]. For example, the professional caregivers always explicitly explained and acknowledged that VITA produced the sounds as no harmful responses were observed. Furthermore, the results illustrated how VITA and SAM offered multisensorial experiences stimulating interest and curiosity in people with dementia to explore and engage with the devices. The emotional experience as a result of interaction may be of greater value than the interaction with the object itself, as people in mid to advanced stages of dementia also seek connection through the object to other people $[36,79,106]$, their senses and feelings $[64,66,78]$, and reacquaintance with self through sensory engagement with the material world $[64,108]$.

These insights relate to the unsettled discussion about the often critiqued notion of 'make-believe', the tendency of interventions to intentionally deceive people with dementia for benevolent reasons such as safety or welfare [60]. Professional caregivers often use deception such as white lies or agreeing with false beliefs during everyday interactions with residents over truth-telling as better alternatives to protect and respect residents [31]. These 'makebelieve' approaches are also reflected in technologies for dementia such as robotic animals [8] or Simulated Presence Therapy [20], which aims to reduce loneliness by playing prerecorded conversations of family members that people with dementia can listen to with a non-functioning telephone [40]. While research claims these forms of therapy can reduce behavioral disorders and loneliness $[8,20,26,33,40,94]$, the intentional deception of people with dementia is debated in current design research to what extent it is ethical to deceive people with dementia $[4,25,60]$. We contribute to that discussion by arguing the need for authenticity and alignment of the aims, aesthetics, and experience offered. A need for authenticity contrasts with technologies for older adults that use a retrospective design that resembles past technologies, as the deception arises when the experience offered does not align with the inferred intent of the product. Therefore, we position the need for authenticity in aesthetics and interaction in residential care environments.

\subsection{Reinforcing Everyday Life}

VITA and SAM were explicitly designed as everyday objects that can be placed in the communal area of the care home. The results revealed how this contextually fitting quality of the research products enabled the caregivers to initiate sessions with VITA and SAM during everyday moments in-between care activities. These small but significant moments can enrich the everyday experience of people living in care facilities. These findings align with how recreational items for care homes can enrich the environment and improve satisfaction for both staff and residents [17]. Therefore, one of the qualities of VITA and SAM is that they do not require exact and prescribed use on set times, but that both devices immerse within the everyday life in a residential care environment and support spontaneous use in response to the situation at hand or the mood of the residents. These objects provide mild stimulation and invite the residents to engage, as SAM is available when residents reside in the communal space, or VITA can be used when a resident is sitting alone. This immersion of technology in everyday life does not aim to alter the everyday experience but reinforces it. However, future research is needed to investigate further how the repeated use of technologies in care settings is experienced by the residents and can culminate into home-like and social habits.

Similar to our results, research on the domestication of technology revealed how artifacts should not disrupt the environment and need to fit with the infrastructural layers of space, service, or stuff [102] and reinforce a sense of home [98]. For instance, a wall-sized display can fit within a particular space and provide a rich, immersive visual context carefully managed by the care staff, which can become a part of the everyday routines in a care home [92]. However, technology for residential dementia care is often impacted by how the care home is perceived as a clinical and medical environment [87]. The governance of products in these spaces is strictly regulated, focusing on function in clinical and medical terms, at the expense of aesthetics, usability, and user experience [82]. The qualities of SAM and VITA provided an emotional attachment to enhance the user experience and provide people living in residential care a sense of home, comfort, and connection with fellow residents. Therefore, people with dementia also value home-like everyday products or objects in a residential care environment as this ensures the qualities of the home remain within a context that is too often perceived as clinical.

\subsection{Community-Driven Use in Practice}

In both studies, the professional caregivers were initiators in presenting the technology to the residents and initiating its use. Research argues that inclusive technologies empower people with dementia in using technologies matching their sensorimotor skills, e.g. $[11,19,70]$. Furthermore, research also shows that the individual with dementia is central in their ecology of care, consisting of 
relatives, informal and professional caregivers who have emotional needs to be considered $[51,55,106,110]$. In addition to the experience of the person with dementia, the professional caregivers' perspectives need to be considered since they play a vital role in promoting technology and making it part of their daily care practice $[55,61,86]$. VITA and SAM contribute to this by offering low-barrier use through their visibility and availability in the care space and the simple interface that caters to the varying technical skills of professional caregivers. If the care staff experience technology as trouble-free and easy-to-use, they can further spark interest and motivate others in using technology in dementia care practice and offer accessible interventions that happen daily [61].

VITA and SAM were research products co-developed and cofunded by care organizations and improved based on the feedback gathered during the field studies to be adopted for long-term use. This collaboration with care practice contributes to the longer-term experience facilitated by VITA and SAM in the care homes by offering the continued use of the research products to the care organizations. Often, interventions stop when the study ends, and residents and caregivers might experience a loss of potential benefits that were experienced during the study [50]. Close collaboration with care facilities in developing technology can create a reciprocal value exchange between stakeholders [63], as recent research emphasizes that the approach of professional caregivers heavily influences the perceived role and characteristics of technology [29, 55]. Therefore, we argue that collaboration between research and care practice is crucial in motivating professional caregivers to embrace new technologies and encourage them to contribute to new interventions. Establishing a community within the care organization that can learn and share experiences about technology supports adopting research products within everyday care. This approach provides a potential answer to the ethical challenges of research in care facilities on maintaining the beneficial impact of technology after a research project ends [50].

\section{CONCLUSION}

In this paper, we report on our findings on evaluating two research products VITA and SAM, and discuss how technology can offer meaningful, social, and sensory engagement in daily care for people in mid to advanced stages of dementia. Based on these findings, we identify design implications that highlight the need for aesthetics in care, authentic experiences, reinforcing everyday life, and community-driven use in a long-term care environment. Future research is necessary to investigate further the effect and sustainable impact of such technology within residential care facilities. We argue that the development of technology in collaboration with care organizations is crucial as highly finished research products that caregivers can use independently on a long-term basis are vital to understanding what technology can offer for this environment. Our contribution to existing work is to challenge presumptions on technology in residential dementia care settings by foregrounding how the possibilities for technology in care can culminate in warmfelt everyday experiences. We aim to motivate the development of technology that addresses and enhances everyday experiences in health-related settings.

\section{ACKNOWLEDGMENTS}

This research was partly funded by ZonMw in the Create Health Program, as part of the 'Everyday Sounds of Dementia' project (443001122), and partly funded by Mijzo care organization. We thank all participants, the care professionals and care organizations Archipel, Pleyade and Mijzo for their involvement in this study.

\section{REFERENCES}

[1] Alzheimer Association. 2019. 2019 Alzheimer's disease facts and figures. Alzheimer's Dement. 15, 3 (March 2019), 321-387. DOI:https://doi.org/10.1016/j. jalz.2019.01.010

[2] Leah Armstrong, Jocelyn Bailey, Guy Julier, and Lucy Kimbell. 2014. Social design futures: HEI research and the AHRC. (2014).

[3] Arlene J. Astell, Maggie P. Ellis, Norman Alm, Richard Dye, and Gary Gowans. 2010. Stimulating People with Dementia to Reminisce Using Personal and Generic Photographs. Int. F. Comput. Heal. 1, 2 (2010), 177-198. DOI:https: //doi.org/10.1504/IJCIH.2010.037461

[4] Arlene Jean Astell. 2006. Technology and personhood in dementia care. Qual. Ageing 7, 1 (2006), 15-25. DOI:https://doi.org/10.1108/14717794200600004

[5] Amee Baird and Séverine Samson. 2015. Music and dementia. In Progress in Brain Research, Eckart Altenmüller, Stanley Finger and François Boller (eds.). Elsevier, 207-235. DOI:https://doi.org/10.1016/bs.pbr.2014.11.028

[6] Amee Baird and William Forde Thompson. 2018. The Impact of Music on the Self in Dementia. F. Alzheimers. Dis. 61, 3 (May 2018), 827-841. DOI:https: //doi.org/10.3233/JAD-170737

[7] Jeffrey Bardzell. 2009. Interaction criticism and aesthetics. In Proceedings of the 27th international conference on Human factors in computing systems - CHI 09 (CHI '09), ACM Press, New York, New York, USA, 2357. DOI:https://doi.org/10. $1145 / 1518701.1519063$

[8] V Bernabei, D De Ronchi, T La Ferla, F Moretti, L Tonelli, B Ferrari, M Forlani, and A R Atti. 2013. Animal-assisted interventions for elderly patients affected by dementia or psychiatric disorders: A review. F. Psychiatr. Res. 47, 6 (2013), 762-773. DOI:https://doi.org/10.1016/j.jpsychires.2012.12.014

[9] Ashok J. Bharucha, Vivek Anand, Jodi Forlizzi, Mary Amanda Dew, Charles F. Reynolds, Scott Stevens, and Howard Wactlar. 2009. Intelligent Assistive Technology Applications to Dementia Care: Current Capabilities, Limitations, and Future Challenges. Am. F. Geriatr. Psychiatry 17, 2 (February 2009), 88-104. DOI:https://doi.org/10.1097/JGP.0b013e318187dde5

[10] Thomas Binder, Eva Brandt, Pelle Ehn, and Joachim Halse. 2015. Democratic design experiments: between parliament and laboratory. CoDesign 11, 3-4 (2015), 152-165.

[11] Stephanie Blackman, Claudine Matlo, Charisse Bobrovitskiy, Ashley Waldoch, Mei Lan Fang, Piper Jackson, Alex Mihailidis, Louise Nygård, Arlene Astell, and Andrew Sixsmith. 2016. Ambient Assisted Living Technologies for Aging Well: A Scoping Review. f. Intell. Syst. 25, 1 (January 2016), 55. DOI:https://doi.org/10. 1515/jisys-2014-0136

[12] Rita Maldonado Branco, Joana Quental, and Óscar Ribeiro. 2017. Personalised participation: an approach to involve people with dementia and their families in a participatory design project. CoDesign 13, 2 (2017), 127-143. DOI:https: //doi.org/10.1080/15710882.2017.1310903

[13] Rens Brankaert, Gail Kenning, Daniel Welsh, Sarah Foley, James Hodge, and David Unbehaun. 2019. Intersections in HCI, Design and Dementia: Inclusivity in Participatory Approaches. In Companion Publication of the 2019 on Designing Interactive Systems Conference 2019 Companion (DIS '19 Companion), Association for Computing Machinery, New York, NY, USA, 357-360. DOI:https://doi.org/10.1145/3301019.3319997

[14] Virginia Braun and Victoria Clarke. 2006. Using thematic analysis in psychology. Qual. Res. Psychol. 3, 2 (January 2006), 77-101. DOI:https://doi.org/10.1191/ 1478088706qp063oa

[15] Dawn Brooker. 2003. What is person-centred care in dementia? Rev. Clin. Gerontol. 13, 03 (August 2003), 215-222. DOI:https://doi.org/10.1017/ S095925980400108X

[16] Dawn J Brooker, Rosemary J Woolley, and David Lee. 2007. Enriching opportunities for people living with dementia in nursing homes: An evaluation of a multi-level activity-based model of care. Aging Ment. Health 11, 4 (July 2007), 361-370. DOI:https://doi.org/10.1080/13607860600963679

[17] Linda L Buettner. 1999. Simple Pleasures: A multilevel sensorimotor intervention for nursing home residents with dementia. Am. F. Alzheimer's Dis. 14, 1 (January 1999), 41-52. DOI:https://doi.org/10.1177/153331759901400103

[18] Angela Byers. 2011. Visual aesthetics in dementia. Int. F. Art Ther. 16, 2 (December 2011), 81-89. DOI:https://doi.org/10.1080/17454832.2011.602980

[19] Suzanne Cahilla, Jurate Macijauskieneb, Aase Marit Nygårdc, Jon Paul Faulknera, and Inger Hagend. 2007. Technology in dementia care. Technol. Disabil. 19, 2-3 (April 2007), 55-60. DOI:https://doi.org/10.3233/tad-2007-192-302 
[20] Lois Camberg, Patricia Woods, Wee Lock Ooi, Ann Hurley, Ladislav Volicer Jane Ashley, Germaine Odenbeimer, and Kevin McIntyre. 1999. Evaluation of simulated presence: A personalized approach to enhance well-being in persons with Alzheimer's disease. 7. Am. Geriatr. Soc. 47, 4 (April 1999), 446-452. DOI:https://doi.org/10.1111/j.1532-5415.1999.tb07237.x

[21] Jiska Cohen-Mansfield, Maha Dakheel-Ali, and Marcia S Marx. 2009. Engagement in persons with dementia: the concept and its measurement. Am. F. Geriatr. Psychiatry 17, 4 (April 2009), 299-307. DOI:https://doi.org/10.1097/JGP. 0b013e31818f3a52

[22] Lesley Collier and Anke Jakob. 2017. The Multisensory Environment (MSE) in Dementia Care: Examining Its Role and Quality From a User Perspective. HERD Heal. Environ. Res. Des. F. 10, 5 (October 2017), 39-51. DOI:https://doi.org/10. $1177 / 1937586716683508$

[23] Jiamin Dai and Karyn Moffatt. 2020. Making Space for Social Sharing: Insights from a Community-Based Social Group for People with Dementia. In Proceedings of the 2020 CHI Conference on Human Factors in Computing Systems (CHI '20), Association for Computing Machinery, New York, NY, USA, 1-13. DOI:https //doi.org/10.1145/3313831.3376133

[24] Boyd H. Davis and Dena Shenk. 2015. Beyond Reminiscence: Using Generic Video to Elicit Conversational Language. Am. F. Alzheimer's Dis. Other Dementiasr 30, 1 (February 2015), 61-68. DOI:https://doi.org/10.1177/1533317514534759

[25] Anna M Day, Ian A James, Thomas D Meyer, and David R Lee. 2011. Do people with dementia find lies and deception in dementia care acceptable? Aging Ment Health 15, 7 (September 2011), 822-829. DOI:https://doi.org/10.1080/13607863. 2011.569489

[26] Abhilash K Desai and George T Grossberg. 2001. Recognition and Management of Behavioral Disturbances in Dementia. Prim. Care Companion 7. Clin. Psychiatry 3, 3 (June 2001), 93-109. DOI:https://doi.org/10.4088/pcc.v03n0301

[27] Jan Dewing. 2007. Participatory research: A method for process consent with persons who have dementia. Dementia 6, 1 (February 2007), 11-25. DOI:https: //doi.org/10.1177/1471301207075625

[28] Jelle van Dijk and Caroline Hummels. 2017. Designing for Embodied Being-inthe-World: Two Cases, Seven Principles and One Framework. In Proceedings of the Eleventh International Conference on Tangible, Embedded, and Embodied Interaction (TEI '17), Association for Computing Machinery, New York, NY, USA 47-56. DOI:https://doi.org/10.1145/3024969.3025007

[29] Emma Dixon and Amanda Lazar. 2020. Approach Matters: Linking Practitioner Approaches to Technology Design for People with Dementia. In Proceedings of the 2020 CHI Conference on Human Factors in Computing Systems (CHI '20), Association for Computing Machinery, New York, NY, USA, 1-15. DOI:https: //doi.org/10.1145/3313831.3376432

[30] Kees Dorst. 2015. Frame innovation: Create new thinking by design. MIT press.

[31] Rebecca Dresser. 2021. A Tangled Web: Deception in Everyday Dementia Care. 7 Law, Med. \& Ethics 49, 2 (2021), 257-262. DOI:https://doi.org/10.1017/jme.2021.35

[32] [32]Sam Fazio, Douglas Pace, Janice Flinner, and Beth Kallmyer. 2018. The Fundamentals of Person-Centered Care for Individuals With Dementia. Gerontologist 58, suppl 1 (January 2018), S10-S19. DOI:https://doi.org/10.1093/geront/gnx122

[33] Yuan Feng, Emilia I Barakova, Suihuai Yu, Jun Hu, and G W Rauterberg. 2020 Effects of the Level of Interactivity of a Social Robot and the Response of the Augmented Reality Display in Contextual Interactions of People with Dementia Sensors 20, 13 (2020), 3771.

[34] Yuan Feng, Suihuai Yu, Dirk van de Mortel, Emilia Barakova, Jun Hu, and Matthias Rauterberg. 2019. LiveNature: Ambient Display and Social RobotFacilitated Multi-Sensory Engagement for People with Dementia. In Proceedings of the 2019 on Designing Interactive Systems Conference - DIS '19, ACM Press, New York, New York, USA, 1321-1333. DOI:https://doi.org/10.1145/3322276.3322331

[35] Sarah Foley, John McCarthy, and Nadia Pantidi. 2019. The Struggle for Recognition in Advanced Dementia: Implications for Experience-Centered Design ACM Trans. Comput. Interact. 26, 6 (November 2019), 1-29. DOI:https://doi.org/ $10.1145 / 3359594$

[36] Sarah Foley, Nadia Pantidi, and John McCarthy. 2019. Care and design: An ethnography of mutual recognition in the context of advanced dementia. In Conference on Human Factors in Computing Systems - Proceedings, ACM Press, New York, New York, USA, Paper 610, 13 pages. DOI:https://doi.org/10.1145/ 3290605.3300840

[37] Sarah Foley, Nadia Pantidi, and John McCarthy. 2020. Student Engagement in Sensitive Design Contexts: A Case Study in Dementia Care. In Proceedings of the 2020 CHI Conference on Human Factors in Computing Systems (CHI '20), Association for Computing Machinery, New York, NY, USA, 1-13. DOI:https: //doi.org/10.1145/3313831.3376161

[38] Sarah Foley, Daniel Welsh, Nadia Pantidi, Kellie Morrissey, Tom Nappey, and John McCarthy. 2019. Printer Pals: Experience-Centered Design to Support Agency for People with Dementia. In Proceedings of the 2019 CHI Conference on Human Factors in Computing Systems - CHI '19, ACM Press, New York, New York, USA, Paper 404, 1-13. DOI:https://doi.org/10.1145/3290605.3300634

[39] David M Frohlich, Emily Corrigan-Kavanagh, Sarah Campbell, Theopisti Chrysanthaki, Paula Castro, Isabela Zaine, and Maria da Graça Campos Pimentel. 2020. Assistive Media for Well-being. In HCI and Design in the Context of Dementia, Rens Brankaert and Gail Kenning (eds.). Springer International Publishing, Cham, 189-205. DOI:https://doi.org/10.1007/978-3-030-32835-1_12 [40] Kathryn Garland, Edwina Beer, Barbara Eppingstall, and Daniel W. O'Connor. 2007. A comparison of two treatments of agitated behavior in nursing home residents with dementia: Simulated family presence and preferred music. Am. F. Geriatr. Psychiatry 15, 6 (June 2007), 514-521. DOI:https://doi.org/10.1097/01. JGP.0000249388.37080.b4

[41] Karen Gold. 2014. But does it do any good? Measuring the impact of music therapy on people with advanced dementia: (Innovative practice). Dementia 13, 2 (2014), 258-264. DOI:https://doi.org/10.1177/1471301213494512

[42] Hannah L Golden, Jennifer L Agustus, Jennifer M Nicholas, Jonathan M Schott, Sebastian J Crutch, Laura Mancini, and Jason D Warren. 2016. Functional neuroanatomy of spatial sound processing in Alzheimer's disease. Neurobiol. Aging 39, (March 2016), 154-164. DOI:https://doi.org/10.1016/j.neurobiolaging.2015.12. 006

[43] Daniel Gooch, Vikram Mehta, Blaine Price, Ciaran McCormick, Arosha Bandara, Amel Bennaceur, Mohamed Bennasar, Avelie Stuart, Linda Clare, Mark Levine, Jessica Cohen, and Bashar Nuseibeh. 2020. How Are You Feeling? Using Tangibles to Log the Emotions of Older Adults. In Proceedings of the Fourteenth International Conference on Tangible, Embedded, and Embodied Interaction (TEI '20), Association for Computing Machinery, New York, NY, USA, 31-43. DOI:https://doi.org/10.1145/3374920.3374922

[44] Gary Gowans, Jim Campbell, Norm Alm, Richard Dye, Arlene Astell, and Maggie Ellis. 2004. Designing a multimedia conversation aid for reminiscence therapy in dementia care environments. In Extended abstracts of the 2004 conference on Human factors and computing systems - CHI '04, ACM Press, New York, New York, USA, 825-836. DOI:https://doi.org/10.1145/985921.985943

[45] Megan E. Graham. 2018. Re-socialising sound: investigating sound, selfhood and intersubjectivity among people living with dementia in long-term care. Sound Stud. 5, 2 (December 2018), 175-190. DOI:https://doi.org/10.1080/20551940.2018. 1551051

[46] Megan E Graham. 2020. Long-term care as contested acoustical space: Exploring resident relationships and identities in sound. Build. Acoust. 27, 1 (2020), 61-73. DOI:https://doi.org/10.1177/1351010X19890478

[47] Niels Hendriks, Liesbeth Huybrechts, Karin Slegers, and Andrea Wilkinson. 2018. Valuing implicit decision-making in participatory design: A relational approach in design with people with dementia. Design Studies 59, 58-76. DOI:https://doi. org/10.1016/j.destud.2018.06.001

[48] Niels Hendriks, Karin Slegers, and Pieter Duysburgh. 2015. Codesign with people living with cognitive or sensory impairments: a case for method stories and uniqueness. CoDesign 11, 1 (January 2015), 70-82. DOI:https://doi.org/10.1080/ 15710882.2015.1020316

[49] James Hodge, Madeline Balaam, Sandra Hastings, and Kellie Morrissey. 2018. Exploring the Design of Tailored Virtual Reality Experiences for People with Dementia. In Proceedings of the 2018 CHI Conference on Human Factors in Computing Systems (CHI '18), ACM Press, New York, New York, USA, Paper 514, 1-13. DOI:https://doi.org/10.1145/3173574.3174088

[50] James Hodge, Sarah Foley, Rens Brankaert, Gail Kenning, Amanda Lazar, Jennifer Boger, and Kellie Morrissey. 2020. Relational, Flexible, Everyday: Learning from Ethics in Dementia Research. In Proceedings of the 2020 CHI Conference on Human Factors in Computing Systems (CHI '20), Association for Computing Machinery, New York, NY, USA, 1-16. DOI:https://doi.org/10.1145/3313831.3376627

[51] James Hodge, Kyle Montague, Sandra Hastings, and Kellie Morrissey. 2019. Exploring Media Capture of Meaningful Experiences to Support Families Living with Dementia. In Proceedings of the 2019 CHI Conference on Human Factors in Computing Systems - CHI '19, ACM Press, New York, New York, USA, 1-14. DOI:https://doi.org/10.1145/3290605.3300653

[52] Göran Holst and Ingalill R Hallberg. 2003. Exploring the meaning of everyday life, for those suffering from dementia. Am. 7. Alzheimer's Dis. Other Dementias ${ }^{\circledR} 18$, 6 (November 2003), 359-365. DOI:https://doi.org/10.1177/153331750301800605

[53] Maarten Houben, Rens Brankaert, Saskia Bakker, Gail Kenning, Inge Bongers, and Berry Eggen. 2019. Foregrounding Everyday Sounds in Dementia. In Proceedings of the 2019 on Designing Interactive Systems Conference - DIS '19, ACM Press, New York, NY, USA, 71-83. DOI:https://doi.org/10.1145/3322276.3322287

[54] Maarten Houben, Rens Brankaert, Saskia Bakker, Gail Kenning, Inge Bongers, and Berry Eggen. 2020. The Role of Everyday Sounds in Advanced Dementia Care. In Proceedings of the 2020 CHI Conference on Human Factors in Computing Systems, ACM Press, New York, NY, USA, Paper 450, pp. 1-14. DOI:https://doi. org $/ 10.1145 / 3313831.3376577$

[55] Maarten Houben, Rens Brankaert, Gail Kenning, Berry Eggen, and Inge Bongers. 2020. The Perspectives of Professional Caregivers on Implementing Audio-Based Technology in Residential Dementia Care. Int. F. Environ. Res. Public Health 17, 17 (2020), 6333. DOI:https://doi.org/10.3390/ijerph17176333

[56] Stephan Huber, Renate Berner, Martina Uhlig, Peter Klein, and Jörn Hurtienne. 2019. Tangible Objects for Reminiscing in Dementia Care. In Proceedings of the Thirteenth International Conference on Tangible, Embedded, and Embodied Interaction - TEI '19, ACM Press, New York, New York, USA, 15-24. DOI:https: //doi.org/10.1145/3294109.3295632 
[57] Emily S. Ihara, Catherine J. Tompkins, Megumi Inoue, and Sonya Sonneman. 2019. Results from a person-centered music intervention for individuals living with dementia. Geriatr. Gerontol. Int. 19, 1 (January 2019), 30-34. DOI:https //doi.org/10.1111/ggi.13563

[58] Wijnand IJsselsteijn, Ans Tummers-Heemels, and Rens Brankaert. 2020. Warm Technology: A Novel Perspective on Design for and with People Living with Dementia. In HCI and Design in the Context of Dementia, Rens Brankaert and Gail Kenning (eds.). Springer International Publishing, Cham, 33-47. DOI:https: //doi.org/10.1007/978-3-030-32835-1_3

[59] Tom Jenkins, Anna Vallgårarda, Laurens Boer, Sarah Homewood, and Teresa Almeida. 2019. Careful Devices. In Proceedings of the Halfway to the Future Symposium 2019 (HTTF 2019), Association for Computing Machinery, New York, NY, USA. DOI:https://doi.org/10.1145/3363384.3363474

[60] Ike Kamphof and Ruud Hendriks. 2017. Make-believe Matters: Can good dementia care and pretence go together. Retrieved July 2, 2019 from https://www.narcis.nl/publication/RecordID/oai:cris.maastrichtuniversity. nl:publications\%2F21b9f2ec-e9e4-4be8-95ba-193c8a39adbe

[61] C Bezboruah Karabi, Paulson Darla, and Smith Jason. 2014. Management attitudes and technology adoption in long-term care facilities. 7. Health Organ Manag. 28, 3 (January 2014), 344-365. DOI:https://doi.org/10.1108/JHOM-112011-0118

[62] Lisa Kelly and Bill Ahessy. 2021. Reminiscence-Focused Music Therapy to Promote Positive Mood and Engagement and Shared Interaction for People Living With Dementia. Voices A World Forum Music Ther. 21, 2 SE-Research (June 2021). DOI:https://doi.org/10.15845/voices.v21i2.3139

[63] Gail Kenning. 2020. Reciprocal Design. In HCI and Design in the Context of Dementia, Rens Brankaert and Gail Kenning (eds.). Springer International Publishing, Cham, 17-32. DOI:https://doi.org/10.1007/978-3-030-32835-1_2

[64] Pia C. Kontos. 2004. Ethnographic reflections on selfhood, embodiment and Alzheimer's disease. Ageing Soc. 24, 6 (November 2004), 829-849. DOI:https: //doi.org/10.1017/S0144686X04002375

[65] Amanda Lazar, Raymundo Cornejo, Caroline Edasis, and Anne Marie Piper. 2016. Designing for the third hand: Empowering older adults with cognitive impairments through creating and sharing. In DIS 2016 - Proceedings of the 2016 ACM Conference on Designing Interactive Systems, ACM Press, New York, New York, USA, 1047-1058. DOI:https://doi.org/10.1145/2901790.2901854

[66] Amanda Lazar, Caroline Edasis, and Anne Marie Piper. 2017. A Critical Lens on Dementia and Design in HCI. In Proceedings of the 2017 CHI Conference on Human Factors in Computing Systems (CHI '17), ACM Press, New York, New York, USA, 2175-2188. DOI:https://doi.org/10.1145/3025453.3025522

[67] Amanda Lazar, Jessica L. Feuston, Caroline Edasis, and Anne Marie Piper. 2018. Making as Expression: Informing Design with People with Complex Communication Needs through Art Therapy. In Proceedings of the 2018 CHI Conference on Human Factors in Computing Systems - CHI '18, ACM Press, New York, New York, USA, Paper 351, 1-16. DOI:https://doi.org/10.1145/3173574.3173925

[68] Amanda Lazar, Hilaire Thompson, and George Demiris. 2014. A systematic review of the use of technology for reminiscence therapy. Health Educ. Behav. 41, 1 Suppl (October 2014), 51S-61S. DOI:https://doi.org/10.1177/1090198114537067

[69] Amanda Lazar, Austin L Toombs, Kellie Morrissey, Gail Kenning, Jennifer Boger, and Rens Brankaert. 2018. HCIxDementia Workshop: Engaging People Living with Dementia. In Extended Abstracts of the 2018 CHI Conference on Human Factors in Computing Systems (CHI EA '18), Association for Computing Machinery, New York, NY, USA. DOI:https://doi.org/10.1145/3170427.3170613

[70] Mary Jane Lovering. 1990. Alzheimer's disease and outdoor space: Issues in environmental design. Am. 7. Alzheimer's Care Relat. Disord. Res. 5, 3 (March 1990), 33-40. DOI:https://doi.org/10.1177/153331759000500307

[71] Tom Luyten, Susy Braun, Susan van Hooren, and Luc de Witte. 2018. How groups of nursing home residents respond to "the CRDL": a pilot study. F. Enabling Technol. 12, 4 (December 2018), 145-154. DOI:https://doi.org/10.1108/JET-052018-0025

[72] Tom Luyten, Susy Braun, Gaston Jamin, Susan van Hooren, and Luc de Witte 2017. How nursing home residents with dementia respond to the interactive art installation 'VENSTER': a pilot study. Disabil. Rehabil. Assist. Technol. (August 2017), 1-8. DOI:https://doi.org/10.1080/17483107.2017.1290701

[73] Anna Meroni. 2007. Creative Communities. People inventing sustainable ways of living. Edizioni Polidesign.

[74] Alex Mihailidis, Jennifer N Boger, Tammy Craig, and Jesse Hoey. 2008. The $\mathrm{COACH}$ prompting system to assist older adults with dementia through handwashing: An efficacy study. BMC Geriatr. 8, 1 (December 2008), 28. DOI:https: //doi.org/10.1186/1471-2318-8-28

[75] Susan L. Mitchell, Joan M. Teno, Dan K. Kiely, Michele L. Shaffer, Richard N. Jones, Holly G. Prigerson, Ladislav Volicer, Jane L. Givens, and Mary Beth Hamel. 2009. The clinical course of advanced dementia. N. Engl. F. Med. 361, 16 (2009), 1529-1538. DOI:https://doi.org/10.1056/NEJMoa0902234

[76] Kellie Morrissey, Amanda Lazar, Jennifer Boger, and Austin Toombs. 2017 HCIxDementia Workshop: The Role of Technology and Design in Dementia. In Proceedings of the 2017 CHI Conference Extended Abstracts on Human Factors in Computing Systems (CHI EA '17), Association for Computing Machinery, New
York, NY, USA, 484-491. DOI:https://doi.org/10.1145/3027063.3027083

[77] Kellie Morrissey and John McCarthy. 2015. Creative and Opportunistic Use of Everyday Music Technologies in a Dementia Care Unit. In Proceedings of the 2015 ACM SIGCHI Conference on Creativity and Cognition - C\&C '15, ACM Press, New York, New York, USA, 295-298. DOI:https://doi.org/10.1145/2757226.2757228

[78] Kellie Morrissey, John McCarthy, and Nadia Pantidi. 2017. The Value of Experience-Centred Design Approaches in Dementia Research Contexts. In Proceedings of the 2017 CHI Conference on Human Factors in Computing Systems (CHI '17), ACM Press, New York, New York, USA, 1326-1338. DOI:https: //doi.org/10.1145/3025453.3025527

[79] Kellie Morrissey, Gavin Wood, David Green, Nadia Pantidi, and John McCarthy. 2016. 'I'm a rambler, I'm a gambler, I'm a long way from home': The Place of Props, Music, and Design in Dementia Care. In Proceedings of the 2016 ACM Conference on Designing Interactive Systems - DIS '16, ACM Press, New York, New York, USA, 1008-1020. DOI:https://doi.org/10.1145/2901790.2901798

[80] Ali Mohammad Mosadeghrad. 2014. Factors influencing healthcare service quality. Int. f. Heal. policy Manag. 3, 2 (July 2014), 77-89. DOI:https://doi.org/10. 15171/ijhpm.2014.65

[81] Claudia Müller, Cornelius Neufeldt, David Randall, and Volker Wulf. 2012. ICTDevelopment in Residential Care Settings: Sensitizing Design to the Life Circumstances of the Residents of a Care Home. In Proceedings of the SIGCHI Conference on Human Factors in Computing Systems (CHI '12), Association for Computing Machinery, New York, NY, USA, 2639-2648. DOI:https://doi.org/10.1145/ 2207676.2208655

[82] Sigrid Nakrem, Marit Solbjør, Ida Nilstad Pettersen, and Hanne Hestvik Kleiven. 2018. Care relationships at stake? Home healthcare professionals' experiences with digital medicine dispensers - a qualitative study. BMC Health Serv. Res. 18, 1 (2018), 26. DOI:https://doi.org/10.1186/s12913-018-2835-1

[83] Johanna M H Nijsten, Ruslan Leontjevas, Martin Smalbrugge, Raymond T C M Koopmans, and Debby L Gerritsen. 2019. Apathy and health-related quality of life in nursing home residents. Qual. Life Res. 28, 3 (2019), 751-759. DOI:https: //doi.org/10.1007/s11136-018-2041-y

[84] Zena O'Connor. 2020. Color Design and Dementia: Harnessing HCI to Improve Environmental Visual Literacy BT - HCI and Design in the Context of Dementia. In Rens Brankaert and Gail Kenning (eds.). Springer International Publishing, Cham, 223-235. DOI:https://doi.org/10.1007/978-3-030-32835-1_14

[85] William Odom, Ron Wakkary, Youn-kyung Lim, Audrey Desjardins, Bart Hengeveld, and Richard Banks. 2016. From Research Prototype to Research Product. In Proceedings of the 2016 CHI Conference on Human Factors in Computing Systems (CHI '16), Association for Computing Machinery, New York, NY, USA, 2549-2561. DOI:https://doi.org/10.1145/2858036.2858447

[86] Hans C Ossebaard and Lisette Van Gemert-Pijnen. 2016. eHealth and quality in health care: implementation time. Int. 7. Qual. Heal. Care 28, 3 (2016), 415-419. DOI:https://doi.org/10.1093/intqhe/mzw032

[87] Jeannette Pols and Ingunn Moser. 2009. Cold technologies versus warm care? On affective and social relations with and through care technologies. Alter 3, 2 (2009), 159-178. DOI:https://doi.org/10.1016/j.alter.2009.01.003

[88] Sydney Pratte, Anthony Tang, and Lora Oehlberg. 2021. Evoking Empathy: A Framework for Describing Empathy Tools. In Proceedings of the Fifteenth International Conference on Tangible, Embedded, and Embodied Interaction (TEI '21), Association for Computing Machinery, New York, NY, USA. DOI:https: //doi.org/10.1145/3430524.3440644

[89] Alfredo Raglio, Stefania Filippi, Daniele Bellandi, and Marco Stramba-Badiale. 2014. Global music approach to persons with dementia: evidence and practice. Clin. Interv. Aging 9, (2014), 1669-1676. DOI:https://doi.org/10.2147/CIA.S71388

[90] Assumpta A Ryan, Claire O McCauley, Elizabeth A Laird, Aideen Gibson, Maurice D Mulvenna, Raymond Bond, Brendan Bunting, Kevin Curran, and Finola Ferry. 2018. 'There is still so much inside': The impact of personalised reminiscence, facilitated by a tablet device, on people living with mild to moderate dementia and their family carers. Dementia 19, 4 (September 2018), 1131-1150. DOI:https://doi.org/10.1177/1471301218795242

[91] Alba Sánchez, José C Millán-Calenti, Laura Lorenzo-López, and Ana Maseda. 2012. Multisensory Stimulation for People With Dementia: A Review of the Literature. Am. F. Alzheimer's Dis. Other Dementias ${ }^{\circledR} 28,1$ (December 2012), 7-14. DOI:https://doi.org/10.1177/1533317512466693

[92] Corina Sas, Nigel Davies, Sarah Clinch, Peter Shaw, Mateusz Mikusz, Madeleine Steeds, and Lukas Nohrer. 2020. Supporting Stimulation Needs in Dementia Care through Wall-Sized Displays. In Proceedings of the 2020 CHI Conference on Human Factors in Computing Systems (CHI '20), Association for Computing Machinery, New York, NY, USA, 1-16. DOI:https://doi.org/10.1145/3313831.3376361

[93] Kimberly Johanna Schelle, Carolina Gomez Naranjo, Martijn ten Bhömer, Oscar Tomico, and Stephan Wensveen. 2015. Tactile Dialogues: Personalization of Vibrotactile Behavior to Trigger Interpersonal Communication. In Proceedings of the Ninth International Conference on Tangible, Embedded, and Embodied Interaction - TEI '14, ACM Press, New York, New York, USA, 637-642. DOI:https: //doi.org/10.1145/2677199.2687894

[94] Hugo Simão and Tiago Guerreiro. 2019. MATY: Designing An Assistive Robot for People with Alzheimer's. In Extended Abstracts of the 2019 CHI Conference 
on Human Factors in Computing Systems - CHI '19, ACM Press, New York, New York, USA, 1-6. DOI:https://doi.org/10.1145/3290607.3313016

[95] Nicholas R Simmons-Stern, Rebecca G Deason, Brian J Brandler, Bruno S Frus tace, Maureen K O'Connor, Brandon A Ally, and Andrew E Budson. 2012. Music-based memory enhancement in Alzheimer's Disease: Promise and limitations. Neuropsychologia 50, 14 (2012), 3295-3303. DOI:https://doi.org/10.1016/j. neuropsychologia.2012.09.019

[96] Wina Smeenk, Janienke Sturm, and Berry Eggen. 2018. Empathic handover: how would you feel? Handing over dementia experiences and feelings in empathic co-design. CoDesign 14, 4 (October 2018), 259-274. DOI:https://doi.org/10.1080/ 15710882.2017.1301960

[97] Luma Tabbaa, Chee Siang Ang, Vienna Rose, Panote Siriaraya, Inga Stewart, Keith G. Jenkins, and Maria Matsangidou. 2019. Bring the Outside In: Providing Accessible Experiences Through VR for People with Dementia in Locked Psychiatric Hospitals. In Proceedings of the 2019 CHI Conference on Human Factors in Computing Systems - CHI '19, ACM Press, New York, New York, USA, 1-15. DOI:https://doi.org/10.1145/3290605.3300466

[98] Leila Takayama, Caroline Pantofaru, David Robson, Bianca Soto, and Michae Barry. 2012. Making Technology Homey: Finding Sources of Satisfaction and Meaning in Home Automation. In Proceedings of the 2012 ACM Conference on Ubiquitous Computing (UbiComp '12), Association for Computing Machinery, New York, NY, USA, 511-520. DOI:https://doi.org/10.1145/2370216.2370292

[99] Kristine Theurer, W. Ben Mortenson, Robyn Stone, Melinda Suto, Virpi Timonen, and Julia Rozanova. 2015. The need for a social revolution in residential care. $\mathcal{F}$ Aging Stud. 35, (December 2015), 201-210. DOI:https://doi.org/10.1016/J.JAGING. 2015.08.011

[100] Myrte Thoolen, Rens Brankaert, and Yuan Lu. 2019. Sentic: A Tailored Interface Design for People with Dementia to Access Music. In Companion Publication of the 2019 on Designing Interactive Systems Conference 2019 Companion - DIS '19 Companion, ACM Press, New York, New York, USA, 57-60. DOI:https://doi.org/ $10.1145 / 3301019.3325152$

[101] Myrte Thoolen, Rens Brankaert, and Yuan Lu. 2020. AmbientEcho: Exploring Interactive Media Experiences in the Context of Residential Dementia Care. In Proceedings of the 2020 ACM Designing Interactive Systems Conference (DIS '20), Association for Computing Machinery, New York, NY, USA, 1495-1508. DOI:https://doi.org/10.1145/3357236.3395432

[102] Peter Tolmie and Andy Crabtree. 2008. Deploying Research Technology in the Home. In Proceedings of the 2008 ACM Conference on Computer Supported Cooperative Work (CSCW '08), Association for Computing Machinery, New York, NY, USA, 639-648. DOI:https://doi.org/10.1145/1460563.1460662

[103] Päivi Topo. 2009. Technology studies to meet the needs of people with dementia and their caregivers: A literature review. Journal of Applied Gerontology 28, 5-37. DOI:https://doi.org/10.1177/0733464808324019

[104] Cathy Treadaway and Gail Kenning. 2016. Sensor e-textiles: person centered co-design for people with late stage dementia. Work. with Older People 20, 2
(June 2016), 76-85. DOI:https://doi.org/10.1108/WWOP-09-2015-0022

[105] Naoko Tsunoda, Mamoru Hashimoto, Tomohisa Ishikawa, Ryuji Fukuhara, Seiji Yuki, Hibiki Tanaka, Yutaka Hatada, Yusuke Miyagawa, and Manabu Ikeda. 2018. Clinical Features of Auditory Hallucinations in Patients With Dementia With Lewy Bodies: A Soundtrack of Visual Hallucinations. 7. Clin. Psychiatry 79, 3 (2018). DOI:https://doi.org/10.4088/JCP.17m11623

[106] David Unbehaun, Konstantin Aal, Daryoush Daniel Vaziri, Peter David Tolmie, Rainer Wieching, David Randall, and Volker Wulf. 2020. Social Technology Appropriation in Dementia: Investigating the Role of Caregivers in Engaging People with Dementia with a Videogame-Based Training System. In Proceedings of the 2020 CHI Conference on Human Factors in Computing Systems (CHI '20), Association for Computing Machinery, New York, NY, USA, 1-15. DOI:https: //doi.org/10.1145/3313831.3376648

[107] David Unbehaun, Daryoush Daniel Vaziri, Konstantin Aal, Rainer Wieching, Peter Tolmie, and Volker Wulf. 2018. Exploring the Potential of Exergames to affect the Social and Daily Life of People with Dementia and their Caregivers. In Proceedings of the 2018 CHI Conference on Human Factors in Computing Systems (CHI '18), ACM Press, New York, New York, USA, Paper 62, 1-15. DOI:https: //doi.org/10.1145/3173574.3173636

[108] Jayne Wallace, Anja Thieme, Gavin Wood, Guy Schofield, and Patrick Olivier. 2012. Enabling self, intimacy and a sense of home in dementia: An Enquiry into Design in a Hospital Setting. In Proceedings of the 2012 ACM annual conference on Human Factors in Computing Systems - CHI '12, ACM Press, New York, New York, USA, 2629. DOI:https://doi.org/10.1145/2207676.2208654

[109] Jayne Wallace, Peter C. Wright, John McCarthy, David Philip Green, James Thomas, and Patrick Olivier. 2013. A design-led inquiry into personhood in dementia. In Proceedings of the SIGCHI Conference on Human Factors in Computing Systems - CHI '13, ACM Press, New York, New York, USA, 2617-2626. DOI:https://doi.org/10.1145/2470654.2481363

[110] Daniel Welsh, Kellie Morrissey, Sarah Foley, Roisin McNaney, Christos Salis, John McCarthy, and John Vines. 2018. Ticket to Talk: Supporting Conversation between Young People and People with Dementia through Digital Media. In Proceedings of the 2018 CHI Conference on Human Factors in Computing Systems - CHI '18 (CHI '18), ACM Press, New York, New York, USA, 1-14. DOI:https: //doi.org/10.1145/3173574.3173949

[111] Bob Woods, Laura O'Philbin, Emma M. Farrell, Aimee E. Spector, and Martin Orrell. 2018. Reminiscence therapy for dementia. Cochrane Database Syst. Rev. 3 (March 2018). DOI:https://doi.org/10.1002/14651858.CD001120.pub3

[112] Peter Wright, Jayne Wallace, and John McCarthy. 2008. Aesthetics and Experience-Centered Design. ACM Trans. Comput. Interact. 15, 4 (December 2008). DOI:https://doi.org/10.1145/1460355.1460360

[113] John Zimmerman, Jodi Forlizzi, and Shelley Evenson. 2007. Research through design as a method for interaction design research in HCI. In Proceedings of the SIGCHI conference on Human factors in computing systems - CHI '07, ACM Press, New York, New York, USA, 493. DOI:https://doi.org/10.1145/1240624.1240704 